\title{
Clinical Utility of Serum Human Epidermal Growth Factor Recep- tor Type 2 Testing as a Marker of Therapeutic Response in Tissue HER2-Positive Breast Cancer Patients
}

\author{
Seiichi Mokuyasu ${ }^{1^{*}}$ and Yasuhiro Suzuki \\ ${ }^{1}$ Department of Clinical Laboratory, Tokai University Hospital, Kanagawa, Japan \\ ${ }^{2}$ Department of Breast and Endocrine Surgery, Tokai University School of Medicine, Kanagawa, Japan
}

*Corresponding author: Seiichi Mokuyasu, Department of Clinical Laboratory, Tokai University Hospital, 143 Shimokasuya, Isehara, Kanagawa 259-1193, Japan, Tel: +81-463-93-1121, Fax: +81-463-93-3580, E-mail: mokuyasu@is.icc.u-tokai.ac.jp

\begin{abstract}
Background: Human Epidermal growth factor Receptor type 2 (HER2) is over expressed in $20.0-30.0 \%$ of breast cancers and is currently evaluated histopathologically. Immunohistochemistry and fluorescence in situ hybridization require invasive enucleation of the tumor tissue and may be affected by heterogeneity. Serum marker tests are more objective because of the uniformity of the study material. Serum HER2 levels are important for breast cancer care. However, the clinical utility of serum HER2 testing is unclear. We evaluated serum HER2 as a marker of therapeutic response in breast cancer.

Methods: Serum HER2 levels were measured in 64 tissue HER2-positive breast cancer patients during routine care. Relationships between serum HER2 levels, clinical stage, tumor diameter, therapeutic response, and Distant Metastasis (DM) were analyzed.

Results: Serum HER2 levels correlated with therapeutic response. An association was observed between serum HER2 levels and tumor diameter. Serum HER2 levels were significantly higher in patients with DM than in those without DM.

Conclusions: Serum HER2 levels are associated with therapeutic response, tumor diameter, and DM. We confirm the clinical utility of serum HER2 testing for monitoring therapeutic response and disease progression in patients with breast cancer.
\end{abstract}

\section{Keywords}

Breast cancer, Distant metastasis, Human epidermal growth factor receptor type 2, Serum marker, Therapeutic response

\section{Abbreviations}

HER2: Human Epidermal Growth Factor Receptor type 2; ECD: Extracellular Ligand-Binding Domain; IHC: Immunohistochemistry; FISH: Fluorescence In Situ Hybridization; DM: Distant Metastasis

\section{Introduction}

Human Epidermal growth factor Receptor type 2 (HER2) is a glycoprotein of $185 \mathrm{kDa}$ that comprises an Extracellular ligand-binding Domain (ECD), a transmembrane domain, and an intracellular domain [1,2]. HER2 functions as a transmembrane receptor and tyrosine kinase that is activated by the binding of its ligand to the ECD and autophosphorylation of its tyrosine residue [3], leading to the nuclear transmission of intracellular signals. HER2 is expressed at low levels in normal cells, and is involved in cell proliferation, differentiation, and growth. HER2 overexpression leads to neoplastic transformation and malignancy [4].

HER2 overexpression occurs in $20.0-30.0 \%$ of breast cancers, usually as a result of gene amplification [4,5], and is associated with a poor prognosis. Therefore, an accurate diagnosis is crucial for breast cancer patients [4].

In Japan, therapeutic agents that molecularly target HER2 (e.g., trastuzumab, lapatinib, pertuzumab, and trastuzumab emtansine) have been developed in rapid succession since 2001 [6]. Therefore, a need has arisen for a test that can accurately diagnose HER2-positive breast cancer patients [7]. HER2-positive breast cancer is detected based on HER2 protein overexpression using Immunohistochemistry (IHC) or HER2 gene amplification using Fluorescence In Situ Hybridization (FISH) [8]. IHC and FISH require invasive enucleation of the tumor tissue and may be affected by heterogeneity [9]; there is also the potential for mismatches to occur between technicians [10].

Citation: Mokuyasu S, Suzuki Y (2017) Clinical Utility of Serum Human Epidermal Growth Factor Receptor Type 2 Testing as a Marker of Therapeutic Response in Tissue HER2-Positive Breast Cancer Patients. Int J Cancer Clin Res 4:089. doi.org/10.23937/2378-3419/1410089

Received: September 21, 2017; Accepted: November 16, 2017; Published: November 18, 2017

Copyright: (c) 2017 Mokuyasu S, et al. This is an open-access article distributed under the terms of the Creative Commons Attribution License, which permits unrestricted use, distribution, and reproduction in any medium, provided the original author and source are credited. 
Table 1: Patient characteristics.

\begin{tabular}{|l|l|}
\hline Characteristic & Patients $(\boldsymbol{n}=\mathbf{6 4})$ \\
\hline Age (years), median (range) & $59.5(30-82)$ \\
\hline Gender, $\boldsymbol{n}$ (\%) & \\
\hline Male & $0(0.0)$ \\
\hline Female & $64(100.0)$ \\
\hline Clinical stage, $\boldsymbol{n}$ (\%) & \\
\hline I & $7(10.9)$ \\
\hline II & $27(42.2)$ \\
\hline III & $24(37.5)$ \\
\hline IV & $6(9.4)$ \\
\hline Therapeutic response, $\boldsymbol{n}$ (\%) & \\
\hline CR & $27(42.2)$ \\
\hline PR & $8(12.5)$ \\
\hline SD & $17(26.6)$ \\
\hline PD & $12(18.7)$ \\
\hline DM, $\boldsymbol{n}$ (\%) & \\
\hline Present & $30(46.9)$ \\
\hline Absent & $34(53.1)$ \\
\hline Tissue HER2 status, $\boldsymbol{n}(\%)$ & \\
\hline Positive & $64(100.0)$ \\
\hline Negative & $0(0.0)$ \\
\hline Serum HER2 status, $\boldsymbol{n}$ (\%) & \\
\hline Positive & $19(29.7)$ \\
\hline Negative & $45(70.3)$ \\
\hline Trastuzumab administration, $\boldsymbol{n}(\%)$ & \\
\hline Yes & $64(100.0)$ \\
\hline No & $0(0.0)$ \\
\hline CR: Comple Ros & \\
\hline
\end{tabular}

CR: Complete Response; DM: Distant Metastasis; HER2: Human Epidermal Growth Factor Receptor type 2; PD: Progressive Disease; PR: Partial Response; SD: Stable Disease.

HER2 testing using the ADVIA Centaur system was approved by the United States Food and Drug Administration in 2003. The HER2 ECD that is released into the serum can now be quantitatively measured by chemiluminescent immunoassays using blood samples [11]. Evaluation of serum HER2 levels is more advantageous than IHC or FISH, because it is less invasive and does not require tumor tissue sampling [12]. Additionally, high serum HER2 levels in tissue HER2-negative breast cancer patients can predict the development of metastatic tumors. Even with HER2-negative primary cancer, high serum HER2 levels after distant metastasis could suggest the possibility of positive tissue HER2 status in the metastatic cancer site. Therefore, this method may be useful for reevaluating HER2 status in metastatic tissue $[12,13]$. Moreover, needle biopsy is not always possible for all metastatic lesions. Serum HER2 testing using blood samples is advantageous in that it can be conducted more frequently than tissue HER2 testing. However, the clinical utility of serum HER2 testing is unclear. Therefore, we evaluated serum HER2 as a marker of therapeutic response in tissue HER2-positive breast cancer patients from Japan.

\section{Methods}

\section{Study design}

This work is an extension of our previous reports $[14,15]$ on the study of drug-induced cardiotoxicity in breast cancer, the study of serum HER2 in tissue HER2-negative breast cancer patients. We measured serum HER2 levels in 220 breast cancer patients from Japan and analyzed the relationships between serum HER2 levels, clinical stage, tumor diameter, therapeutic response, and Distant Metastasis (DM). The study design was approved by the Institutional Review Board for Clinical Research at Tokai University School of Medicine (Kanagawa, Japan). All participants provided informed written consent. Research was conducted in accordance with the Helsinki Declaration.

\section{Patients and samples}

Tissue and serum samples were obtained from 64 female patients with tissue HER2-positive breast cancer (median age, 59.5 [range, 30.0-82.0] years), who were examined in the Department of Breast and Endocrine Surgery (Tokai University School of Medicine, Kanagawa, Japan) between February 2010 and January 2014 (Table 1). Blood samples were collected routinely from the start of treatment during outpatient treatment course. Subjects were excluded if they had ovarian, lung, prostate, or gastric cancer. Serum samples were separated and cryopreserved at $-80.0^{\circ} \mathrm{C}$.

\section{Immunohistochemistry}

IHC staining was performed on target tissue sections using the HER2 antibody (Ventana I-VIEW Pathway HER2 [4B5]; Roche Diagnostics K.K., Tokyo, Japan). The HER2 protein was detected through an antigen-antibody reaction $[16,17]$.

\section{Fluorescence in situ hybridization}

The copy number of the HER2 gene was detected in interphase nuclei of tumor cellsusing a fluorescently labeled DNA probe (PathVysion HER-2 DNA Probe Kit; Abbott Co., Ltd., Tokyo, Japan) $[17,18]$ in formalin-fixed paraffin-embedded tissue sections.

\section{Tissue HER2 status}

Tissue HER2 status was considered positive with an IHC score of $3+$ (positive cells: $>30.0 \%$ ) $/ 2+$ (positive cells: $10.0-30.0 \%$ ) and a HER2/centromere 17 gene ratio of $\geq 2.2$ on FISH [16].

\section{Serum HER2 levels}

Serum HER2 levels were measured during routine hospital visits using the ADVIA Centaur XP System and ADVIA Centaur HER2/neu assay (Siemens Healthcare Diagnostics K.K., Tokyo, Japan). Briefly, serum HER2 forms an immune complex after reacting with the acridinium-ester-labeled anti-HER2 antibody among the labeling reagents and the fluorescein-labeled anti-HER2 antibody among the fluorescein-conjugated reagents, as well as, the anti-fluorescein antibody binding to magnetic particles among the solid-phase reagents [11]. The immune complex is washed after bound/free separa- 
tion and serum HER2 levels are measured based on the quantity of chemiluminescence that is generated by the addition of an oxidant or supplementary oxidant. Serum HER2 levels of $\geq 15.3 \mathrm{ng} / \mathrm{mL}$ were considered positive [19].

\section{Tumor diameter}

Tumor diameter was measured as the maximum diameter of the tissues demonstrating invasion within the excised tumor.

\section{Chemotherapy}

An anthracycline regimen, followed by taxane regimen, is the standard neoadjuvant and adjuvant chemotherapy treatment. Taxane, combined with 1-year administration of trastuzumab, was used in the tissue HER2-positive patients. The chemotherapy regimens chosen by the physicians included: Bevacizumab + paclitaxel, paclitaxel, docetaxel, eribulin, vinorelbine, gemcitabine, or oral 5-fluorouracil. In addition, anti-HER2 agents were used concomitantly with chemotherapy in tissue HER2-positive breast cancer patients with disease progression or recurrence. Chemotherapy drugs were also administered to the patients with triple negative breast cancer or lymph node metastasis who were in Stage I-III.

\section{Therapeutic response}

Therapeutic response was evaluated in accordance with the General Rules for Clinical and Pathological Recording of Breast Cancer (17 $7^{\text {th }}$ edition) [20]: Complete response (all target lesions, including secondary tumor-related changes, are eliminated), partial response (the sum of the diameters of the target lesion is reduced by $\geq 30.0 \%$ in comparison to the sum of the diameters before initiating treatment), stable disease (neither a reduction in tumor size constituting a partial response nor an increase in tumor size constituting progressive disease), and progressive disease (the sum of the diameters of the target lesion is increased by $\geq 20.0 \%$ in comparison to the time when the sum of the diameters was at its smallest and/or the sum of the diameters is increased by an absolute value of $\geq 5.0 \mathrm{~mm}$ ).

\section{Statistical analyses}

Mann-Whitney $U$ tests were used to compare the non-normally distributed groups. Relationships were analyzed using Spearman's rank-order correlation coefficients. Statistical analyses were conducted using Statistical Package for the Social Sciences (software version 23.0; IBM Corp., Armonk, NY, USA). A P < 0.05 was considered significant.

\section{Results}

\section{Relationships between serum HER2 levels, clinical stage, and therapeutic response}

Relationships between serum HER2 levels and clin-

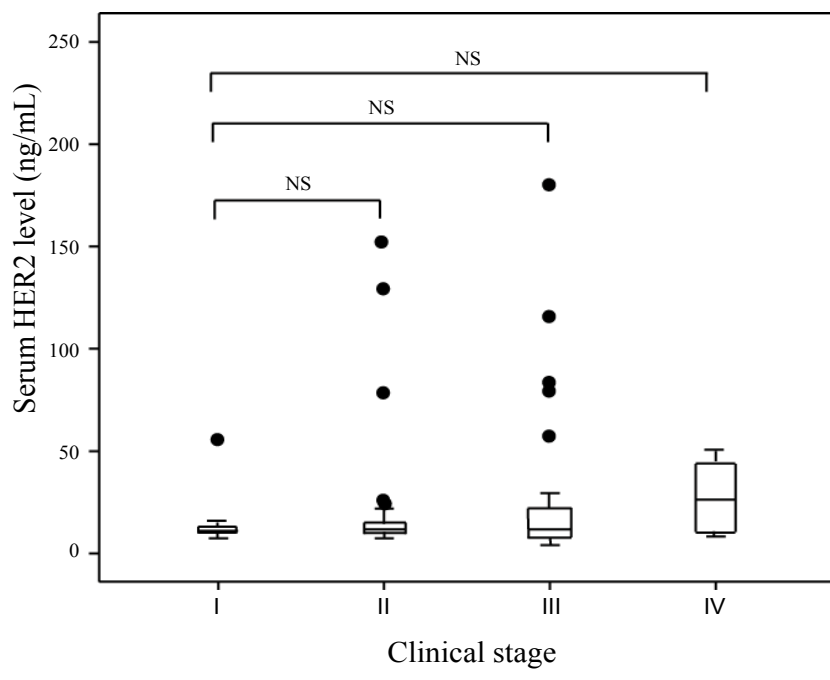

Tissue HER2-positive breast cancer patients

Figure 1: Relationships between serum Human Epidermal Growth Factor Receptor type 2 (HER2) levels and clinical stage in tissue HER2-positive breast cancer patients. NS: Not Significant.

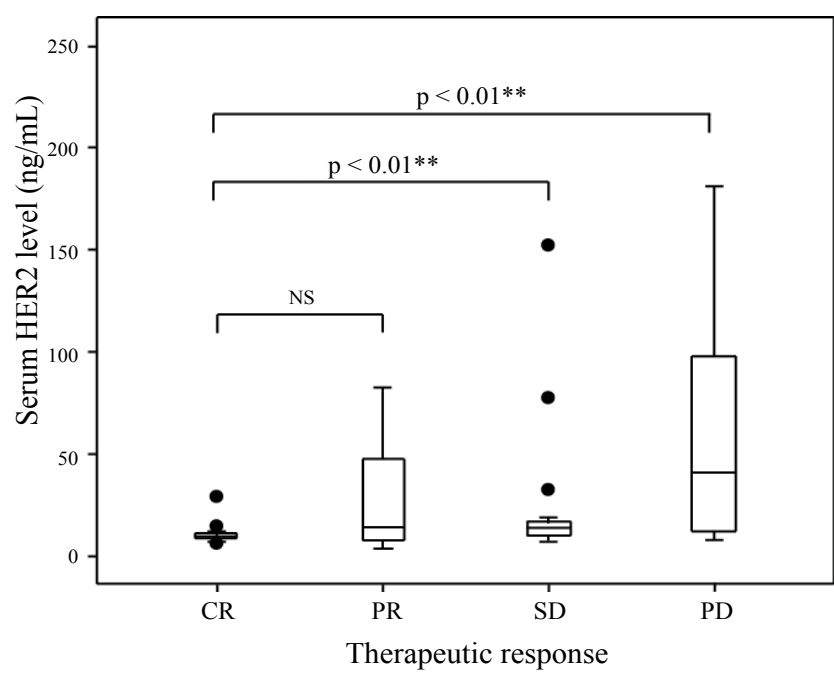

Tissue HER2-positive breast cancer patients

Figure 2: Relationships between serum Human Epidermal Growth Factor Receptor type 2 (HER2) levels and therapeutic response in tissue HER2-positive breast cancer patients. CR: Complete Response; PD: Progressive Disease; PR: Partial Response; SD: Stable Disease; NS: Not Significant.

ical stage were analyzed, with no significant findings (Figure 1). Significant differences in serum HER2 levels and therapeutic response were observed between tissue HER2-positive patients with a complete response and those with stable or progressive disease. No other significant findings were detected (Figure 2).

\section{Relationships between serum HER2 levels, tumor diameter, and DM}

Positive associations between serum HER2 levels and tumor diameter were observed in tissue HER2-positive patients (Figure 3). Serum HER2 levels were significantly higher in patients with DM than those without DM (Figure 4). 


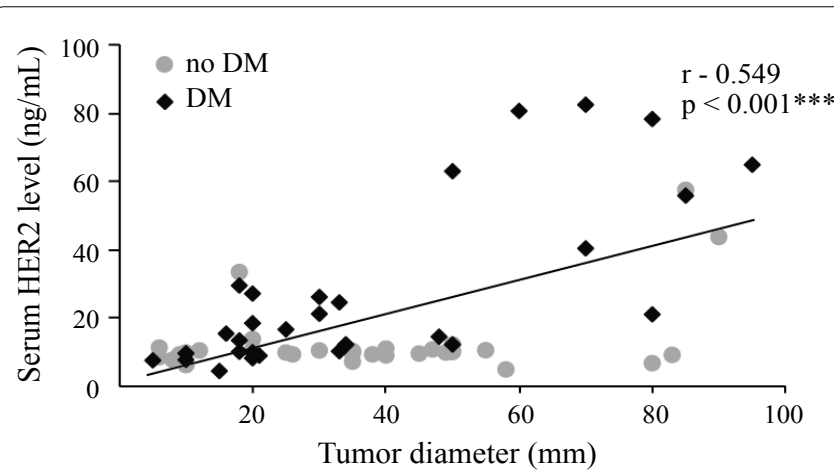

Tissue HER2-positive breast cancer patients

Figure 3: Relationships between serum Human Epidermal Growth Factor Receptor type 2 (HER2) levels and tumor diameter in tissue HER2-positive breast cancer patients. DM: Distant Metastasis.

\section{Discussion}

Currently, IHC, in which the HER2 ECD is immunostained, and FISH, in which amplified HER2 DNA is fluorescently labeled $[16,21]$, are the two most frequently used techniques to evaluate HER2 status in breast cancer patients. HER2 testing is an important tool for administering personalized treatment [16]. However, IHC and FISH require invasive enucleation of the tumor tissue and may be affected by heterogeneity [9]. There is also the potential for mismatches to occur between technicians $[10,22]$. Metastatic breast cancer sites have an increased potential for malignancy and therefore cancer at the distant site could be HER2 positive, even if the primary lesion is HER2 negative. However, needle biopsy cannot always be performed for all metastatic lesions; for these cases, measuring serum HER2 levels may indicate the tissue HER2 status in metastatic lesions. The HER2 ECD is released into the blood from cell surfaces through protease-accelerated shedding [23]. It is detected in the serum by enzyme or chemiluminescent immunoassays [24,25]. In this study, serum HER2 measurements were performed using an assay-based system that is not affected by trastuzumab, lapatinib, pertuzumab, or trastuzumab emtansine. Anti-HER2 antibodies are detected at positions 78-242 on the amino acid chain of the ECD. Since this is separated from positions 529-625, where trastuzumab binds, there is no interference from the administration of trastuzumab [26].

Whilst serum HER2 may be present at low levels in healthy individuals, it is frequently detected at high levels in breast cancer patients [19]. Serum HER2 is also detected in epithelial tumors other than breast cancer $[27,28]$. A consensus regarding the serum HER2 cutoff value has not been established [29]. In Western countries, a cutoff value of $15.0 \mathrm{ng} / \mathrm{mL}$ has been widely adopted from the United States Food and Drug Administration [19], while $15.2 \mathrm{ng} /$ $\mathrm{mL}$ is commonly used in Japan.

We reported in previous reports that high serum HER2 levels in tissue HER2-negative breast cancer patients is associated with clinical condition [15].

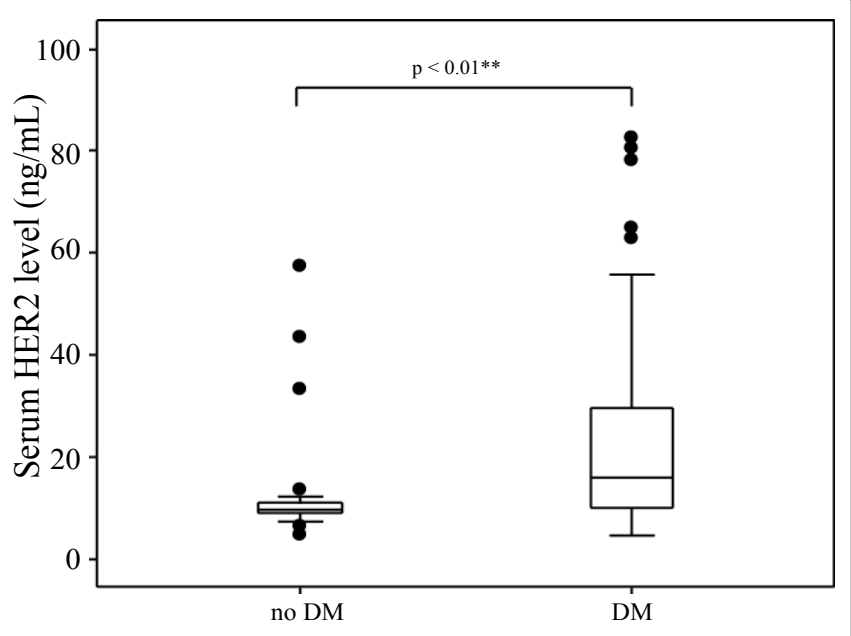

Tissue HER2-positive breast cancer patients

Figure 4: Relationships between serum Human Epidermal Growth Factor Receptor type 2 (HER2) levels and Distant Metastasis (DM) in tissue HER2-positive breast cancer patients.

Since tumor size is related to Stage I-III disease, but not Stage IV disease, it has been suggested that Stage I-III disease may correlate with serum HER2 levels [30]. However, this was not the case in our study.

A significant association was observed between serum HER2 levels and therapeutic response, with high serum HER2 levels correlating with a poor therapeutic response. We postulated that serum HER2 could be a marker of therapeutic response in breast cancer patients. This study did not a specific time-period to measure serum HER2 levels. Future studies are needed to identify the ideal time-period of serum HER2 testing for more accurate define of therapeutic response.

Serum HER2 levels have also been reported to correlate with tissue HER2 status [29,31]. However, this has not always been the case [32]. Differences in serum and tissue HER2 status were observed in this study. Therefore, serum HER2 levels could not be used to predict tissue HER2 status. False evaluation of the tissue HER2 status of the primary tumor (e.g., due to testing inaccuracies or the intratumoral heterogeneity of HER2 expression) could explain this discrepancy [23]. Several studies [33-35] have also suggested that HER2 status may differ between primary and metastatic cancer. HER2-negative primary cancer patients may have HER2-positive DMs, and HER2 overexpression may be lost during metastatic progression $[23,36]$.

We also observed a positive association between serum HER2 levels and tumor diameter in tissue HER2-positive breast cancer patients. Serum HER2 levels were significantly higher in patients with DM than in those without DM. Thus, serum HER2 levels were related to tumor diameter and tumor cell metastasis in tissue HER2-positive patients, with high serum HER2 levels correlating with poor clinical condition. Since increased serum HER2 levels are related to tumor diameter and 
distance metastasis, serum HER2 levels are suggested to be a potential index of metastatic lesions [37]. However, given the wide variety of chemotherapy drugs, administration methods, mechanisms of action, as well as the unclear effect of chemotherapy-induced tumor lysis on serum HER2 levels, further studies are needed.

Currently, trastuzumab is not administered to serum HER2-positive/tissue HER2-negative patients because its effects remain unclear. Since the use of anti-HER2 therapies (e.g., trastuzumab) improves the clinical course of tissue HER2-positive patients, an accurate evaluation of HER2 status is crucial [38]. Whilst the evaluation of tissue HER2 status may be useful for selecting those patients who are mostly likely to benefit from anti-HER2 therapy, such evaluation by IHC or FISH may produce inconsistent results, due to differences in technique among institutions and/or the intratumoral heterogeneity of HER2 expression [9]. Some studies have reported that tissue HER2 status are routinely detected in primary breast cancers, although the positivity was not consistent, having been noted in $10.0-30.0 \%$ of recurrent tumors $[39,40]$. The American Society of Clinical Oncology guidelines suggest that approximately $20.0 \%$ of findings from current HER2 testing methods are inaccurate [10]. Therefore, it is essential to improve the testing techniques for HER2-positive breast cancer patients to provide optimal therapy.

The evaluation of serum HER2 status is less invasive than tissue HER2 status as it does not require tumor tissue sampling. Thus, when tumor tissue sampling is problematic, it may be possible to measure HER2 levels through serum HER2 testing [12]. Since serum HER2 levels reflect the clinical condition of the patient better than carcinoembryonic antigen or cancer antigen 15-3 levels [13], it can be useful to compare serum and tissue HER2 status. Serum HER2 is not a predictive marker of anti-HER2 therapy. However, serum HER2 testing may be beneficial for assessing clinical condition [12,13].

Serum HER2 is associated with therapeutic response, tumor diameter, and DM in Japanese breast cancer patients. Our findings support the clinical utility of serum HER2 testing for monitoring therapeutic response and disease progression in breast cancer patients. However, since the sample size is relatively small, future largescale studies are needed to contribute to breast cancer treatment.

\section{Acknowledgments}

We wish to thank all the patients who participated in this study.

\section{Funding}

None.

\section{Conflicts of Interest}

None declared.

\section{References}

1. Akiyama $T$, Sudo $C$, Ogawara $H$, Toyoshima $K$, Yamamoto $T$ (1986) The product of the human c-erbB-2 gene: a 185-kilodalton glycoprotein with tyrosine kinase activity. Science 232: 1644-1646.

2. Harari D, Yarden $Y(2000)$ Molecular mechanisms underlying ErbB2/HER2 action in breast cancer. Oncogene 19: 6102-6114.

3. Van der Geer P, Hunter T, Lindberg RA (1994) Receptor protein-tyrosine kinases and their signal transduction pathways. Annu Rev Cell Biol 10: 251-337.

4. Slamon DJ, Clark GM, Wong SG, Levin WJ, Ullrich A, et al. (1987) Human breast cancer: Correlation of relapse and survival with amplification of the HER-2/neu oncogene. Science 235: 177-182.

5. Goldhirsch A, Glick JH, Gelber RD, Coates AS, Thürlimann $B$, et al. (2005) Meeting highlights: international expert consensus on the primary therapy of early breast cancer 2005 . Ann Oncol 16: 1569-1583.

6. Slamon DJ, Leyland-Jones B, Shak S, Fuchs H, Paton V, et al. (2001) Use of chemotherapy plus a monoclonal antibody against HER2 for metastatic breast cancer that overexpresses HER2. N Engl J Med 344: 783-792.

7. Wolff AC, Hammond ME, Schwartz JN, Hagerty KL, Allred DC, et al. (2007) American Society of Clinical Oncology/ College of American Pathologists guideline recommendations for human epidermal growth factor receptor 2 testing in breast cancer. Arch Pathol Lab Med 131: 18-43.

8. Wolff AC, Hammond ME, Hicks DG, Dowsett M, McShane LM, et al. (2013) Recommendations for human epidermal growth factor receptor 2 testing in breast cancer: American Society of Clinical Oncology/College of American Pathologists clinical practice guideline update. J Clin Oncol 31: 3997-4013.

9. Perez EA, Roche PC, Jenkins RB, Reynolds CA, Halling $\mathrm{KC}$, et al. (2002) HER2 testing in patients with breast cancer: Poor correlation between weak positivity by immunohistochemistry and gene amplification by fluorescence in situ hybridization. Mayo Clin Proc 77: 148-154.

10. Sauter G, Lee J, Bartlett JM, Slamon DJ, Press MF (2009) Guidelines for human epidermal growth factor receptor 2 testing: biologic and methodologic considerations. J Clin Oncol 27: 1323-1333.

11. Lüftner D, Cheli $C$, Mickelson K, Sampson E, Possinger $K$ (2004) ADVIA Centaur HER-2/neu shows value in monitoring patients with metastatic breast cancer. Int J Biol Markers 19: $175-182$.

12. Carney WP, Bernhardt D, Jasani B (2013) Circulating HER2 Extracellular Domain: A Specific and Quantitative Biomarker of Prognostic Value in all Breast Cancer Patients? Biomark Cancer 5: 31-39.

13. Mokuyasu S, Suzuki Y, Seto T, Miyachi H, Tokuda Y (2012) A comparative clinical evaluation of the assay of serum extracellular domain of HER2 protein using a chemiluminescent immunoassay method in breast cancer patients with or without HER2 protein expression in immunohistochemistry. Rinsho Byori 60: 612-620.

14. Mokuyasu S, Suzuki Y, Kawahara E, Seto T, Tokuda Y (2015) High-sensitivity cardiac troponin I detection for 2 types of drug-induced cardiotoxicity in patients with breast cancer. Breast Cancer 22: 563-569.

15. Mokuyasu S, Suzuki Y, Kawahara E (2016) Clinical utility of measuring serum HER2 level in tissue HER2-negative breast cancer patients. Jpn J Med Tech 65: 181-187. 
16. Wolff AC, Hammond ME, Schwartz JN, Hagerty KL, Allred DC, et al. (2007) American Society of Clinical Oncology/ College of American Pathologists guideline recommendations for human epidermal growth factor receptor 2 testing in breast cancer. Arch Pathol Lab Med 131: 18-43.

17. Ellis IO, Bartlett J, Dowsett M, Humphreys S, Jasani B, et al. (2004) Best Practice No 176: Updated recommendations for HER2 testing in the UK. J Clin Pathol 57: 233-237.

18. Middleton LP, Price KM, Puig P, Heydon LJ, Tarco E, et al. (2009) Implementation of American Society of Clinical Oncology/College of American Pathologists HER2 Guideline Recommendations in a tertiary care facility increases HER2 immunohistochemistry and fluorescence in situ hybridization concordance and decreases the number of inconclusive cases. Arch Pathol Lab Med 133: 775-780.

19. Cook GB, Neaman IE, Goldblatt JL, Cambetas DR, Hussain $M$, et al. (2001) Clinical utility of serum HER-2/neu testing on the Bayer Immuno 1 automated system in breast cancer. Anticancer Res 21: 1465-1470.

20. The Japanese Breast Cancer Society (2012) General rules for clinical and pathological recording of breast cancer. $\left(17^{\text {th }}\right.$ edn), Kanehara, Tokyo.

21. Walker RA, Bartlett JM, Dowsett M, Ellis IO, Hanby AM, et al. (2008) HER2 testing in the UK: Further update to recommendations. J Clin Pathol 61: 818-824.

22. Kroese M, Zimmern RL, Pinder SE (2007) HER2 status in breast cancer-an example of pharmacogenetic testing. J R Soc Med 100: 326-329.

23. Tsé C, Gauchez AS, Jacot W, Lamy PJ (2012) HER2 shedding and serum HER2 extracellular domain: Biology and clinical utility in breast cancer. Cancer Treat Rev 38: 133-142.

24. Yamauchi H, Stearns V, Hayes DF (2001) When is a tumor marker ready for prime time? A case study of c-erbB-2 as a predictive factor in breast cancer. J Clin Oncol 19: 2334-2356.

25. Ludovini V, Gori S, Colozza M, Pistola L, Rulli E, et al. (2008) Evaluation of serum HER2 extracellular domain in early breast cancer patients: correlation with clinicopathological parameters and survival. Ann Oncol 19: 883-890.

26. Payne RC, Allard JW, Anderson-Mauser L, Humphreys JD, Tenney DY, et al. (2000) Automated assay for HER-2/neu in serum. Clin Chem 46: 175-182.

27. Molina R, Jo J, Filella X, Bruix J, Castells A, et al. (1997) Serum levels of C-erbB-2 (HER-2/neu) in patients with malignant and non-malignant diseases. Tumour Biol 18: 188196.

28. Sasaki T, Fuse N, Kuwata T, Nomura S, Kaneko K, et al. (2015) Serum HER2 levels and HER2 status in tumor cells in advanced gastric cancer patients. Jpn J Clin Oncol 45: 43-48.

29. Gioia D, Dresse M, Mayr D, Nagel D, Heinemann V, et al. (2014) Serum HER2 supports HER2-testing in tissue at the time of primary diagnosis of breast cancer. Clin Chim Acta 430: 86-91.

30. Sakamoto G, Inaji H, Akiyama F, Haga S, Hiraoka M, et al. (2005) General rules for clinical and pathological recording of breast cancer 2005. Breast Cancer 12: S1-S27.

31. Kong SY, Nam BH, Lee KS, Kwon Y, Lee ES, et al. (2006) Predicting tissue HER2 status using serum HER2 levels in patients with metastatic breast cancer. Clin Chem 52: 1510-1515.

32. Dittadi R, Zancan M, Perasole A, Gion M (2001) Evaluation of HER-2/neu in serum and tissue of primary and metastatic breast cancer patients using an automated enzyme immunoassay. Int J Biol Markers 16: 255-261.

33. Zidan J, Dashkovsky I, Stayerman C, Basher W, Cozacov C, et al. (2005) Comparison of HER-2 over expression in primary breast cancer and metastatic sites and its effect on biological targeting therapy of metastatic disease. $\mathrm{Br} \mathrm{J}$ Cancer 93: 552-556.

34. Guarneri V, Giovannelli S, Ficarra G, Bettelli S, Maiorana A, et al. (2008) Comparison of HER-2 and hormone receptor expression in primary breast cancers and asynchronous paired metastases: impact on patient management. Oncologist 13: 838-844.

35. Lower EE, Glass E, Blau R, Harman S (2009) HER-2/neu expression in primary and metastatic breast cancer. Breast Cancer Res Treat 113: 301-306.

36. Kmieciak M, Knutson KL, Dumur Cl, Manjili MH (2007) HER-2/neu antigen loss and relapse of mammary carcinoma are actively induced by $\mathrm{T}$ cell-mediated anti-tumor immune responses. Eur J Immunol 37: 675-685.

37. Fehm T, Gebauer G, Jäger W (2002) Clinical utility of serial serum c-erbB-2 determinations in the follow-up of breast cancer patients. Breast Cancer Res Treat 75: 97-106.

38. Esteva FJ, Yu D, Hung MC, Hortobagyi GN (2010) Molecular predictors of response to trastuzumab and lapatinib in breast cancer. Nat Rev Clin Oncol 7: 98-107.

39. Santinelli A, Pisa E, Stramazzotti D, Fabris G (2008) HER2 status discrepancy between primary breast cancer and metastatic sites. Impact on target therapy. Int J Cancer 122: 999-1004.

40. Wilking U, Karlsson E, Skoog L, Hatschek T, Lidbrink E, et al. (2011) HER2 status in a population-derived breast cancer cohort: discordances during tumor progression. Breast Cancer Res Treat 125: 553-561. 